Check for updates

Cite this: RSC Adv., 2017, 7, 53396

\title{
An economic analysis of rice straw microwave pyrolysis for hydrogen-rich fuel gas
}

\author{
Xuhui Li, (D) ${ }^{a}$ Kunquan Li, ${ }^{a}$ Chunlei Geng, ${ }^{a}$ Hamed El Mashad, ${ }^{\text {b }}$ Hua Li ${ }^{\star a}$ \\ and Wenqing Yin*a
}

Rice straw is an abundant biomass resource, and it can produce hydrogen-rich fuel gas through microwave pyrolysis, so it has many potential applications. In this research, the combustion heat of gas per kilogram per kilowatt hour was used as one index to explore the influence of microwave power, moisture content and the length of feedstock. A multi-factor experiment was designed by using a Central Composite Design on Design-Expert 8.0 software. The results show that the gas calorific value increases with moisture content. However, the gas calorific value first increases and then decreases with an increase in microwave power and length. Ignoring the energy consumed during the preparation of the material, the most economic conditions for the production of gas are explored in this paper.

Received 7th October 2017

Accepted 11th November 2017

DOI: $10.1039 / \mathrm{c} 7 \mathrm{ra11034k}$

rsc.li/rsc-advances

pyrolysis, microwave pyrolysis does not need an external heat

\section{Introduction}

As society develops, energy demand increases year by year, and the excessive use of fossil fuels is creating a series of problems such as global warming, sea level rises, acid rain, haze and the increased frequency of extreme weather events. ${ }^{1}$ Thus, it is inevitable that new clean energy sources are increasingly being sought. Because carbon emissions of biomass are considered to be zero, biomass energy is recognized as an environmentally-friendly energy. ${ }^{2,3}$ The global crop straw production yield is above $8 \times 10^{9}$ tons per year, and in China this value is about $7 \times 10^{8}$ tons per year. Furthermore, this value is continuing to rise. ${ }^{4}$ So, crop straw provides one form of renewable energy with wide distribution and excellent production of biomass. However, generally, the bulk density of biomass is quite low (800-900 $\mathrm{kg} \mathrm{m}^{-3}$ for bitumite, $30-40 \mathrm{~kg} \mathrm{~m}^{-3}$ for rice straw, $110 \mathrm{~kg} \mathrm{~m}^{-3}$ for maize straw), and transportation costs are high for direct use, so conversion processes are needed to promote the biomass utilization value. ${ }^{5,6}$ Current research is focused on the use of pyrolysis methods to obtain more valuable products: biogas and biooil. $^{7,8}$ Furthermore, biogas is a high value gas because it is hydrogen-rich. Biogas can be used for gas turbines, fuel cells, etc., and it can be burned to get heat. The combustion process of biogas is easy to control with low carbon emissions, and it does not produce particulate matter.

In recent years, more and more scholars have paid attention to biomass microwave pyrolysis. ${ }^{9-11}$ Compared to traditional

${ }^{a}$ College of Engineering, Nanjing Agricultural University, Nanjing, 210031 China. E-mail: lihua@njau.edu.cn; yinwq@njau.edu.cn

${ }^{b}$ Department of Biological and Agricultural Engineering, University of California, One Shields Avenue, Davis, CA 95616, USA source. Instead of heat conduction moving from the surface to the inside, microwave pyrolysis transfers heat to biomass through the heater method. It generates rapid and uniform heating. As compared to traditional pyrolysis, microwave pyrolysis is more energy-efficient and it produces more hydrogen. ${ }^{12}$ According to Huang's research, microwave pyrolysis rice straw can produce hydrogen-rich gas, with hydrogen content reaching $57 \% .^{13}$ In Lin's research, two different microwave pyrolysis systems were compared, and, for the hydrogen-rich gas, the highest hydrogen content was $56 \%$, while the conversion rate of hydrogen was found to be $67.45 \%,{ }^{14}$ which shows that using microwave to obtain hydrogen-rich fuel gas from pyrolysis rice straw is feasible and efficient. Shang et al. added different additives to sawdust to explore their influence on the pyrolysis process of sawdust. ${ }^{15}$ The results show that additives improved the heating rate, and during the pyrolysis process, additives mainly acted as catalysts. Based on our previous research, adding $\mathrm{ZnCl}_{2}$ to rice straw could raise hydrogen content in microwave pyrolysis gas. ${ }^{16} \mathrm{So}$, in this research, $\mathrm{ZnCl}_{2}(5 \%)$ was added to raw materials as an additive in order to improve efficiency.

Although in recent years microwave pyrolysis biomass has rapidly developed, there has been little research focused on the economic analysis of microwave pyrolysis. Hence, rice straw was used as raw material in this research in order to analyze its microwave pyrolysis products. Design-Expert 8.0 software was adapted to design the CCD test to study the effects of microwave power, water content, and material size on the heating value of gas phase products. We aimed to identify the most economic conditions to achieve the most efficient microwave pyrolysis. 


\section{Experimental section}

Materials

The rice straw used in this study was the late-season rice straw in Nanjing area, Jiangsu, China. After natural drying (the moisture content was $6 \%$ ), the rice straw was treated to the required size by using a pulverizer and scissors. Different moisture content gradients were realized by adding distilled water to the straw. $5 \% \mathrm{ZnCl}_{2}$ was added to all experimental materials as additive. The amount of the samples used in each run was $35 \pm 3 \mathrm{~g}$.

\section{Experimental conditions}

The microwave system used in this study was designed by our laboratory together with Nanjing Jinhaifeng Microwave Technology Ltd. The Agilent 7820A gas chromatography was adapted for real-time detection of produced gas (Fig. 1).

\section{Experimental method}

High purity $\mathrm{N}_{2}(99.99 \%)$ was purged for over 10 minutes to completely expel the air in the microwave pyrolysis oven. The pyrolysis temperature was measured by thermocouple. Related parameters like pyrolysis temperature and microwave power were established according to the experimental design. Airtight syringes were used to transfer the microwave-assisted pyrolysis products into the gas chromatograph for gas analysis. As concentrations of hydrocarbons such as $\mathrm{C}_{2} \mathrm{H}_{4}$ and $\mathrm{C}_{2} \mathrm{H}_{6}$ are extremely low in the gaseous products of biomass pyrolysis, ${ }^{17}$ for the purpose of simplifying analysis, only $\mathrm{CO}, \mathrm{CO}_{2}, \mathrm{H}_{2}$ and $\mathrm{CH}_{4}$ were focused on in this study and a value of $100 \%$ was assumed for their total volume percentage. Because gas production varied under different conditions, a new evaluation index, $Q$, was introduced in this study: the heat generated by the combustion of gas produced by one kilogram of raw materials which provided a kilowatt-hour of electricity during microwave pyrolysis. The formula is as follows:

$$
Q=\frac{\left(10100 \times V_{1}+140000 \times V_{2}+55900 \times V_{3}\right) \times V}{P \times T} \times \eta
$$

where $V_{1}$ is the CO content in gas products; $V_{2}$ is the $\mathrm{H}_{2}$ content; $V_{3}$ is the $\mathrm{CH}_{4}$ content; $V$ is the gas production rate; $P$ is the microwave output power; $\eta$ is microwave conversion efficiency; and $T$ is the time needed for the pyrolysis temperature to reach $750{ }^{\circ} \mathrm{C}$.

The determination method of microwave conversion efficiency: set the microwave pyrolysis system output power at $1 \mathrm{~kW}, 2 \mathrm{~kW}$ and $3 \mathrm{~kW}$, set the run time as 30 minutes, then measure power consumption. The microwave conversion efficiency of this system was found to be $58 \%$.

Because it is difficult to directly measure the gas yield, we calculated the gas yield by measuring solid and liquid products. The formula is as follows:

$$
V=\frac{m-m_{1}-m_{2}}{m} \times 100 \%
$$

where $m$ is the mass of raw materials; $m_{1}$ is the mass of solid products; and $m_{2}$ is the mass of liquid products.

\section{Experimental results and conclusions}

\section{Single factor experiment analysis}

Effect of moisture content on $\boldsymbol{Q}$. In this experiment, the microwave power were $2 \mathrm{~kW}$, straw length were $1 \mathrm{~cm}$, the straw moisture content were $6 \%, 24 \%, 42 \%$ and $60 \%$, the results were shown in Fig. 2. As can be seen in Fig. 2, higher moisture content leads to a higher $Q$. Even though higher moisture content equated to a longer heating time, especially during the drying stage (80-105 $\left.{ }^{\circ} \mathrm{C}\right)$, more microwave energy was consumed, but a higher amount of flammable gases were contained in the gas phase products, so the $Q$ was higher.

Effect of microwave power on $\mathbf{Q}$. In this experiment, the straw length were $1 \mathrm{~cm}$, the straw moisture content were $6 \%$, and the microwave power were $1.5 \mathrm{~kW}, 2 \mathrm{~kW}, 2.5 \mathrm{~kW}$ and $3 \mathrm{~kW}$, the results were shown in Fig. 3. As can be seen in Fig. 3, before $3 \mathrm{~kW}$, higher microwave power leads to the higher $Q$. However, a decrease in microwave power of $3 \mathrm{~kW}$ could be observed. According to the heating rate and product composition, the reason for this might be that at $3 \mathrm{~kW}$, the heating rate and gas

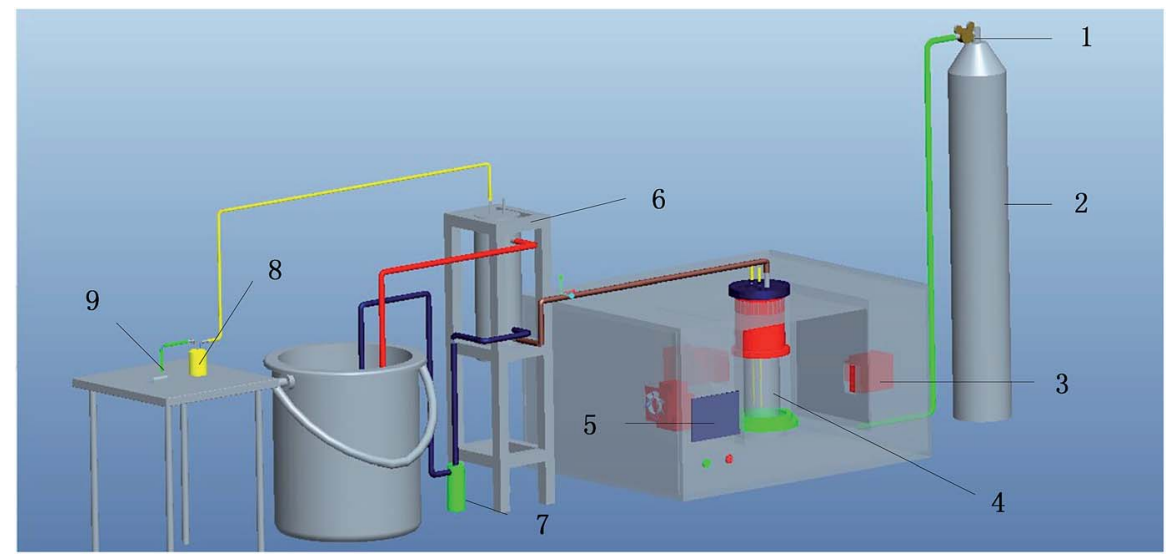

Fig. 1 The microwave pyrolysis system (1) relief valve; (2) nitrogen; (3) microwave generator; (4) reaction chamber; (5) control unit; (6) condenser; (7) circulating pump; (8) gas filter; (9) gas-colleted bag. 


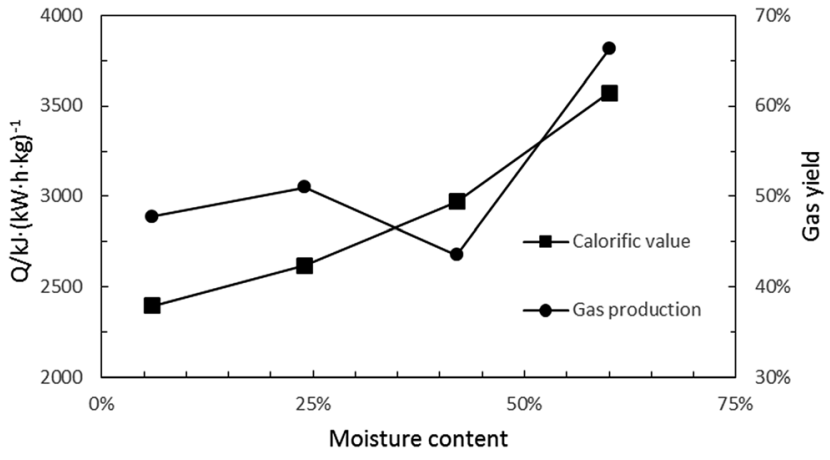

Fig. 2 Effect of moisture content on $Q$ and gas yield.

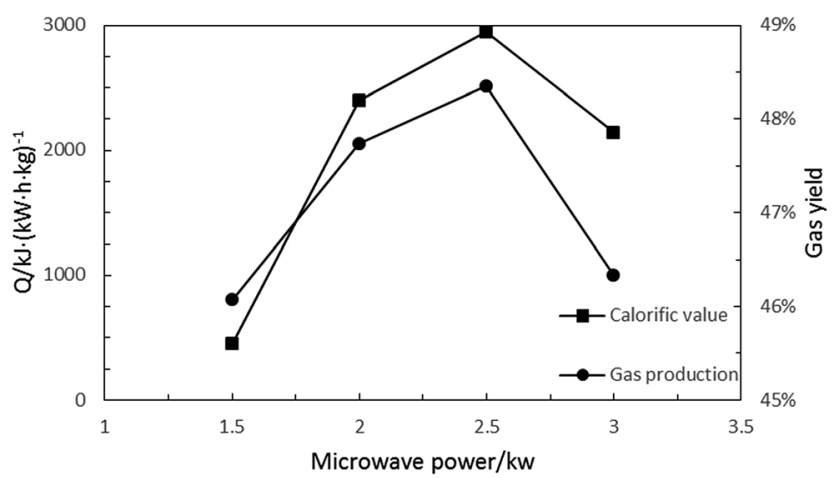

Fig. 3 Effect of microwave power on $Q$ and gas yield.

composition were similar to that at $2.5 \mathrm{~kW}$. That means, compared with $2.5 \mathrm{~kW}$, it took a similar time to reach $750{ }^{\circ} \mathrm{C}$, but the power input was higher, thus, more microwave energy was consumed. What's more, at $3 \mathrm{~kW}$, the gas yield also decreased. Therefore, the $Q$ was lower at $3 \mathrm{~kW}$.

Effect of straw length on $\mathbf{Q}$. In this experiment, the microwave power were $2 \mathrm{~kW}$, straw moisture content were $6 \%$, the straw length were 40 mesh, coarse powder (about $0.2 \mathrm{~cm}$ ), $1 \mathrm{~cm}$ and $3 \mathrm{~cm}$, the results were shown in Fig. 4 . As can be seen, with an increase in length, the $Q$ decreased. By analyzing the heating rate and product composition, it can be observed that, though the gas yield increased with a rice straw length of $3 \mathrm{~cm}$, the gas yield and composition were similar. Furthermore, the heating

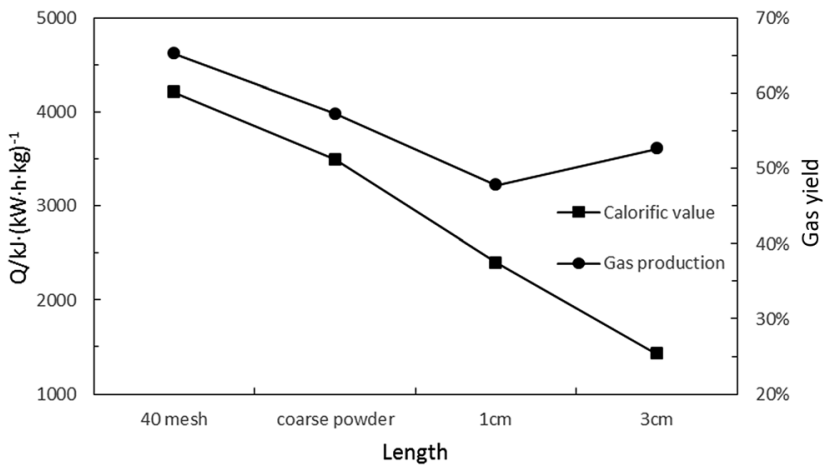

Fig. 4 Effect of straw length on $Q$ and gas yield. rates were also similar. This may because the size increase led to a decline in microwave pyrolysis efficiency (restricted to the reactor volume, large material pyrolysis had a lower pyrolysis efficiency). As the energy consumption of raw materials cannot be quantified, further studies are needed to determine the optimal size.

\section{Multi-factor experiment analysis}

Experimental design. A response surface methodology was applied to determine the most economical conditions for gas using a Central Composite Design (CCD) that was implemented in Design-Expert 8.0 software (StatEase, USA). The effects of microwave power (A), straw moisture content (B), and straw length (C) on $Q$ were determined. The test parameters are listed in Tables 1 and 2.

Results analysis. A regression analysis was conducted to determine the relationship between gas calorific value and microwave power, moisture content and straw length, and their interaction. The regression analysis was conducted using the coded values as presented in follows:

$$
\begin{aligned}
Q= & 1198+7802 A-302 B-2079 C+58 A B \\
& +194 A C-9 B C-2218 A^{2}+3.5 B^{2}+298 C^{2}
\end{aligned}
$$

Table 1 The parameters and levels for the CCD test

\begin{tabular}{lrrrr}
\hline Influence factor & -Alpha & +Alpha & Low & High \\
\hline Microwave power A (kW) & 1.50 & 2.50 & 1.70 & 2.30 \\
Moisture content B (\%) & 20.00 & 60.00 & 28.11 & 51.89 \\
Length C (cm) & 0.01 & 5.00 & 1.02 & 3.99
\end{tabular}

\begin{tabular}{|c|c|c|c|c|}
\hline \multirow[b]{2}{*}{$\begin{array}{l}\text { Test } \\
\text { number }\end{array}$} & \multicolumn{3}{|l|}{ Influence factor } & \multirow{2}{*}{ 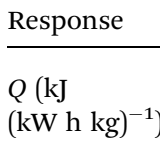 } \\
\hline & $\begin{array}{l}\text { (A) Microwave } \\
\text { power }(\mathrm{kW})\end{array}$ & $\begin{array}{l}\text { (B) Moisture } \\
\text { content (\%) }\end{array}$ & $\begin{array}{l}\text { (C) Length } \\
(\mathrm{cm})\end{array}$ & \\
\hline 1 & 1.50 & 40.00 & 2.50 & 809.204 \\
\hline 2 & 2.00 & 40.00 & 0.01 & 5409.45 \\
\hline 3 & 2.50 & 40.00 & 2.50 & 2356.16 \\
\hline 4 & 1.70 & 51.89 & 3.99 & 3492.5 \\
\hline 5 & 2.30 & 28.11 & 3.99 & 3021.57 \\
\hline 6 & 2.00 & 40.00 & 2.50 & 2524.23 \\
\hline 7 & 2.00 & 40.00 & 2.50 & 3085.71 \\
\hline 8 & 1.70 & 51.89 & 1.02 & 5722.98 \\
\hline 9 & 2.30 & 51.89 & 3.99 & 5233.91 \\
\hline 10 & 2.00 & 60.00 & 2.50 & 4616.8 \\
\hline 11 & 2.00 & 40.00 & 2.50 & 3005.45 \\
\hline 12 & 1.70 & 28.11 & 3.99 & 2195.54 \\
\hline 13 & 2.00 & 40.00 & 2.50 & 3644.34 \\
\hline 14 & 2.30 & 28.11 & 1.02 & 4254.16 \\
\hline 15 & 2.00 & 20.00 & 2.50 & 2480.04 \\
\hline 16 & 2.00 & 40.00 & 2.50 & 2826.78 \\
\hline 17 & 2.00 & 40.00 & 5.00 & 2579.18 \\
\hline 18 & 1.70 & 28.11 & 1.02 & 3675.73 \\
\hline 19 & 2.00 & 40.00 & 2.50 & 2311.18 \\
\hline 20 & 2.30 & 51.89 & 1.02 & 7026.31 \\
\hline
\end{tabular}

Table 2 The design and results of the CCD test 

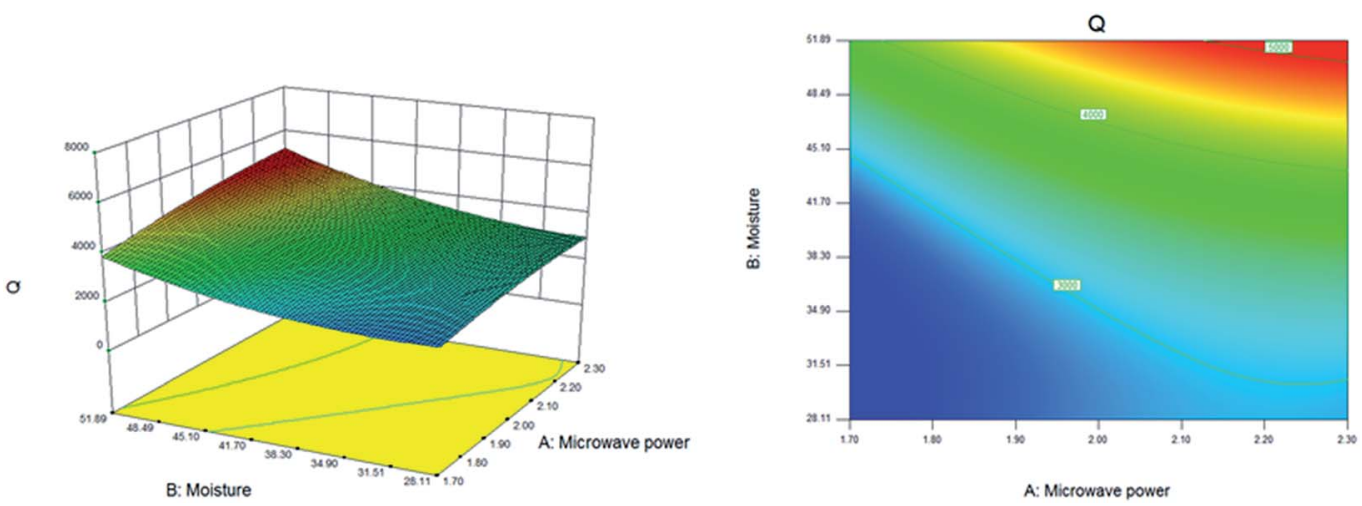

Fig. 5 The response curves and contour lines of $Q$ under different microwave power and moisture contents.

where the $p$-values of $\mathrm{AC}, \mathrm{BC}$ were 0.7761 and 0.5890 . The results suggest that these factors were not significant, so they were removed. The optimized equation is as follows:

$$
\begin{aligned}
Q= & 1200+8300 A-325 B-2100 C+58 A B \\
& -2300 A^{2}+3.5 B^{2}+300 C^{2}
\end{aligned}
$$

The $p$-value of the fitting equation was 0.009 , indicating the fit is good and the model is suitable (because the central composite design method tends to fit the central point, so it is quite normal to find distortions at some endpoints).

As can be seen in Fig. 5, microwave power and moisture content have beneficial effects on $Q$. With an increase in moisture content, the $Q$ increased; but with an increase in microwave power, the $Q$ decreased after rising, and the turning point was around $2.3 \mathrm{~kW}$.

As can be seen in Fig. 6, the moisture content showed an inhibitive and then a positive effect on $Q$. This is probably because when the moisture content increased, in addition to extending the residence time during the drying stage $\left(85-105^{\circ} \mathrm{C}\right)$, the content of combustibles in the gas product also increased, thus increasing the $Q$. With low moisture content, the increase of combustible content in the gas product was not obvious, but with high moisture content, a dramatic rise in combustible content could be observed; thus, the $Q$ firstly decreased then increased as the moisture content increased. It is worth mentioning that the drop in gas calorific value was so little that, overall, it can be concluded that the $Q$ increased as moisture content increased. This is consistent with the single factor experiment results and Fig. 5.

As can be seen in Fig. 6 and 7, the straw length showed an inhibitive and then a positive effect on $Q$. This is probably because the heating rates of small-size straw was higher than that of large-sized straw; thus, the small-sized straw had a higher efficiency than the large-sized straw. As the feed quantity of small-sized straw was higher than that of large-sized straw, the heating rate was lower for small-sized straw, thus reducing the pyrolysis efficiency. So the $Q$ firstly decreased then increased as straw length increased.

Because of the limitations of experimental conditions, all materials were prepared by manual cutting, and the energy consumed during the preparation of materials could not be quantified, so the effect of straw length on energy consumption is not discussed in this study.

\section{Model validation}

By using the optimization function in Design-Expert 8, three factors were defined, with the goal being to maximize the gas calorific value. According to the results given by the software,
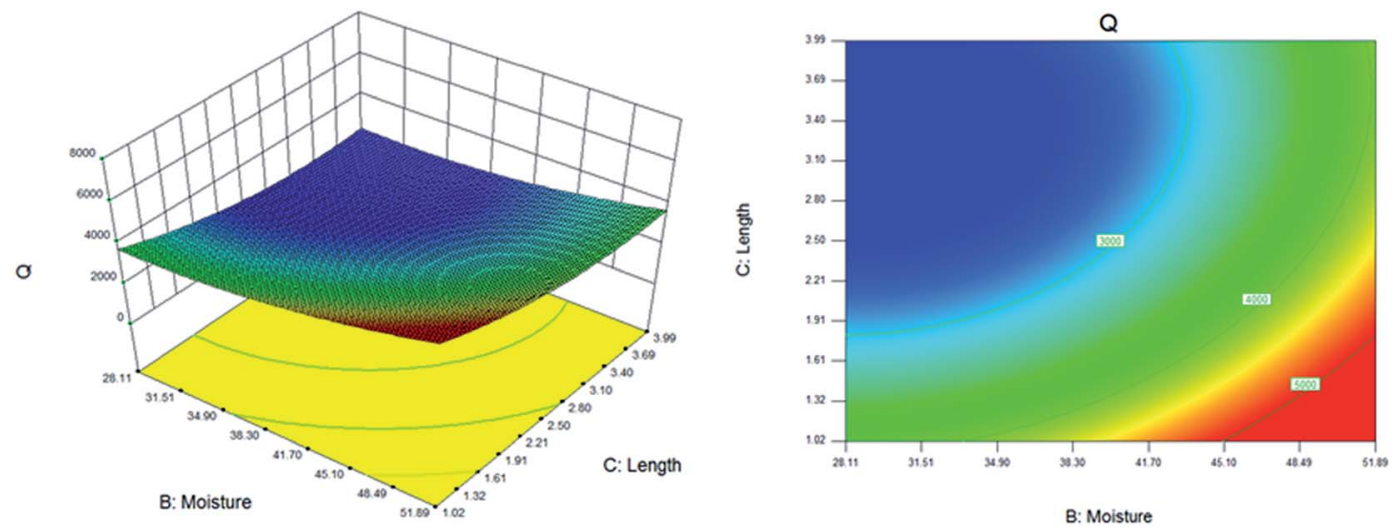

Fig. 6 The response curves and contour lines of $Q$ under different moisture contents and straw lengths. 

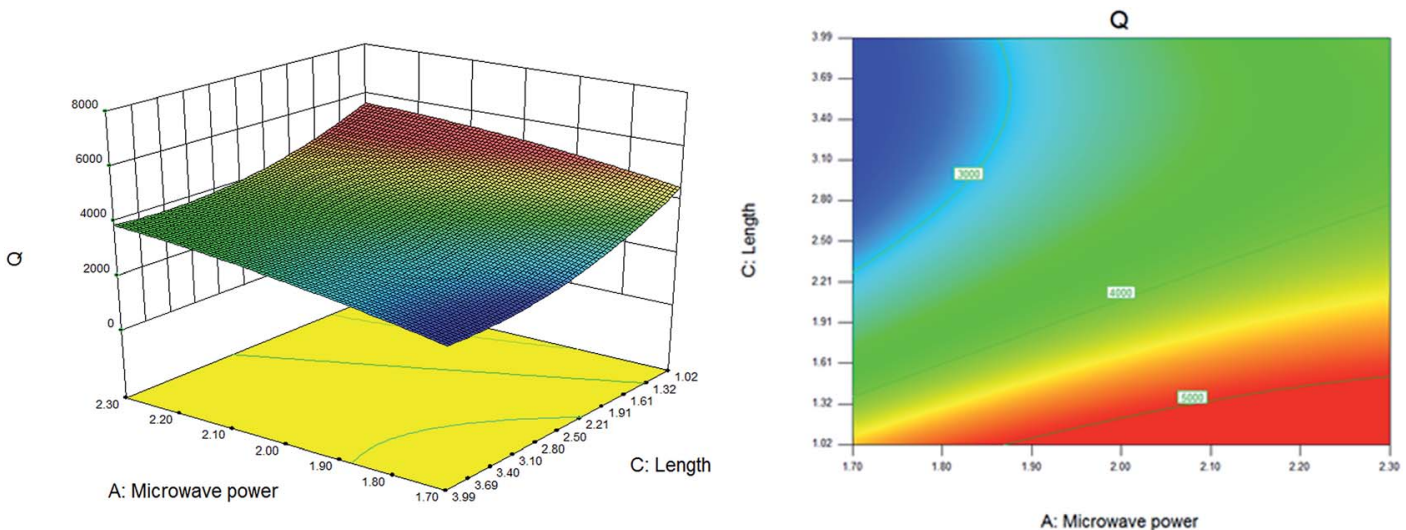

Fig. 7 The response curves and contour lines of $Q$ under different microwave power and straw lengths.

Table 3 The verification test results

\begin{tabular}{lllll}
\hline $\begin{array}{l}\text { Test } \\
\text { no. }\end{array}$ & $\begin{array}{l}Q / \mathrm{kJ} \\
(\mathrm{kW} \mathrm{h} \mathrm{kg})^{-1}\end{array}$ & $\begin{array}{l}\text { AVG/kJ } \\
(\mathrm{kW} \mathrm{h} \mathrm{kg})^{-1}\end{array}$ & $\begin{array}{l}\mathrm{SD} / \mathrm{kJ} \\
(\mathrm{kW} \mathrm{h} \mathrm{kg})\end{array}$ & $\begin{array}{l}\text { Predicated value/kJ } \\
(\mathrm{kW} \mathrm{h} \mathrm{kg})\end{array}$ \\
\hline 1 & 6879.6 & 7394.1 & 365.3 & 6938.9 \\
2 & 7720.8 & & & \\
3 & 7564 & & &
\end{tabular}

the optimization parameters were microwave power A $2.04 \mathrm{~kW}$, moisture content B 60\%, straw length C $1.04 \mathrm{~cm}$. Following these parameters, three repeated verification tests were done. The amount of the samples used in each run was $35 \pm 0.01 \mathrm{~g}$. The Experimental results are shown in Table 3.

As can be seen in Table 3, the standard deviation (SD) was $365.3 \mathrm{~kJ}$, which means the pyrolysis process was stable. The average was $7394.1 \mathrm{~kJ}$, and, according to the model, the predicated value was $6938.9 \mathrm{~kJ}$ (error, 6.2\%). The results suggest that the fit was good and the model was suitable.

\section{Conclusions}

The $Q$ increased as moisture content increased; it first increased and then decreased with microwave power and length. Regarding microwave power, the maximum $Q$ was reached at around $2.3 \mathrm{~kW}$.

The best data fit for $Q$ as a function of microwave power, moisture content and straw length was:

$$
\begin{aligned}
Q= & 1200+8300 A-325 B-2100 C+58 A B-2300 A^{2} \\
& +3.5 B^{2}+300 C^{2}
\end{aligned}
$$

Ignoring the energy consumed during the preparation of material, the most economic conditions to produce gas were as follows: microwave power $2.04 \mathrm{~kW}$, moisture content B $60 \%$, straw length C $1.04 \mathrm{~cm}$, and the $Q$ was $7394.1 \mathrm{~kJ}$.

\section{Conflicts of interest}

There are no conflicts to declare.

\section{Acknowledgements}

This study is financially supported by the Jiangsu Provincial Engineering Laboratory for Biomass Conversion and Process Integration Open Research Funded Projects (JPELBCPI2015002).

\section{References}

1 F. Motasemi and M. T. Afzal, Renewable Sustainable Energy Rev., 2013, 28, 317-330.

2 Y. Huang, P. Chiueh and S. Lo, Sustainable Environ. Res., 2016, 26, 103-109.

3 Y. Fernández and J. A. Menéndez, J. Anal. Appl. Pyrolysis, 2011, 91, 316-322.

4 M. Guangying, Z. Wenju, X. Qinghua and Z. Xinwei, China Herbivore Sci., 2014, 34, 24-27.

5 G. P. Maitan-Alfenas, E. M. Visser and V. M. Guimarães, Curr. Opin. Food Sci., 2015, 1, 44-49.

6 M. Makela, V. Benavente and A. Fullana, Appl. Energy, 2015, 155, 576-584.

7 D. Beneroso, J. M. Bermúdez, A. Arenillas and J. A. Menéndez, Bioresour. Technol., 2013, 144, 240-246.

8 J. E. Omoriyekomwan, A. Tahmasebi and J. Yu, Bioresour. Technol., 2016, 207, 188-196.

9 X. Zhao, W. Wang, H. Liu, C. Ma and Z. Song, Bioresour. Technol., 2014, 158, 278-285.

10 R. Zhou, H. Lei and J. Julson, J. Anal. Appl. Pyrolysis, 2013, 101, 172-176.

11 P. Shuttleworth, V. Budarin, M. Gronnow, J. H. Clark and R. Luque, J. Nat. Gas Chem., 2012, 21, 270-274.

12 Y. Huang, P. Chiueh, W. Kuan and S. Lo, Bioresour. Technol., 2013, 142, 620-624.

13 Y. F. Huang, W. H. Kuan, S. L. Lo and C. F. Lin, Bioresour. Technol., 2008, 99, 8252-8258.

14 Y. Lin, T. Wu, W. Liu and Y. Hsiao, Fuel, 2014, 119, 21-26.

15 H. Shang, R. Lu, L. Shang and W. Zhang, Fuel Process. Technol., 2015, 131, 167-174.

16 H. Li, X. Li, L. Liu, K. Li, X. Wang and H. Li, Int. J. Hydrogen Energy, 2016, 41, 2263-2267.

17 Y. F. Huang, W. H. Kuan, S. L. Lo and C. F. Lin, Bioresour. Technol., 2010, 101, 1968-1973. 